left HJ (Table 1). There were no statistical differences between MRI symptoms of the impairment HJ and US symptoms of coxitis at baseline and after 2 years (Table 2).

Radiographic progression (BASRI-hip $\geq 1$ stage) after 2 years follow-up founded in $7(31,8 \%)$ pts with MRI symptoms of the impairment HJ. There are radiographic progression from normal $\mathrm{HJ}$ to bilateral stage 1 in $5(71,4 \%)$ pts, from bilateral stage 1 to bilateral stage 2 in $2(28,6 \%)$ pts. Mean NSAID index in pts with radiographic progression $(31,8 \%)$ amount $62,2 \%$, while in pts without radiographic progression $-72,5 \%(p=0,2)$.

Conclusions: 1. In patients with early axial spondyloarthritis in two years of observation radiographic progression observed in $31,7 \%$ patients despite on regular intake of NSAIDs. 2. Further studies of the impairment $\mathrm{HJ}$ are required in patients with axial SpA.

Disclosure of Interest: None declared

DOI: 10.1136/annrheumdis-2017-eular.3985

\section{SAT0395 SIMILARITIES AND DIFFERENCES BETWEEN NON-RADIOGRAPHIC AND RADIOGRAPHIC AXIAL SPONDYLOARTHRITIS IN PROOF COHORT}

D. Poddubnyy ${ }^{1}$, R.D. Inman ${ }^{2}$, J. Sieper ${ }^{1}$, S. Akar ${ }^{3}$, S. Muñoz-Fernández ${ }^{4}$, M. Hojnik ${ }^{5} \cdot{ }^{1}$ Charité Universitätsmedizin Berlin, Berlin, Germany: ${ }^{2}$ Toronto Western Hospital, Toronto, Canada; ${ }^{3}$ Izmir Katip Celebi University School of Medicine, Izmir, Turkey; ${ }^{4}$ Hospital Universitario Infanta Sofía, Universidad Europea, Madrid, Spain; ${ }^{5}$ AbbVie, Ljubljana, Slovenia

Background: Previously, some differences between non-radiographic and radiographic axial spondyloarthritis (axSpA) - such as a higher prevalence of females and lower level of acute phase reactants in non-radiographic axSpA (nr-axSpA) have been reported in national observational studies, mostly from Europe.

Objectives: To compare demographic and clinical characteristics of patients (pts) with $\mathrm{nr}-\mathrm{axSpA}$ and radiographic axSpA (ankylosing spondylitis, AS) in a large multinational cohort of pts with recently diagnosed axSpA.

Methods: PROOF is a prospective observational study evaluating clinical and radiographic outcomes in axSpA pts in rheumatology clinical practice in 29 countries. Pts with axSpA fulfilling ASAS classification criteria were eligible if diagnosed $\leq 1$ year prior to study enrolment. Investigator's confidence with the diagnosis of axSpA was ascertained on a numeric rating scale (NRS 0-10) at enrolment and end of follow-up. At baseline, demographic and clinical data related to the diagnosis, disease activity, quality of life and work productivity, as well as conventional radiographs of the sacroiliac joints were collected. Classification as nr-axSpA or AS was based on the results of the assessment of sacroiliac radiographs. Available radiographs were assessed first by a local reader and then by a central reader according to the grading system of the modified New York criteria. In the case of a disagreement in the classification (nr- axSpA or $\mathrm{AS}$ ), the radiograph was evaluated by the 2 nd central reader, who was blinded to the previous assessments and the final classification was made based on the decision of 2 out of 3 readers.

Results: Of the 2126 pts enrolled in PROOF, 1281 (60.3\%) pts were classified as AS and $845(39.7 \%)$ as $\mathrm{nr}$-axSpA according to investigators. The confidence with the diagnosis of axSpA was $8.7 \pm 1.8$. The final classification according to the central assessment of sacroiliac radiographs was confirmed in1583 pts included in this analysis. A total of 987 pts (62.3\%) were classified as AS and 596 (37.7\%) as $n r-a x S p A$. AS pts expectedly had longer symptom duration, more frequently had elevated and higher CRP and were more often male and treated with TNF inhibitors (Table). In addition, HLA-B27 positivity was more frequent among AS pts, while pts with nr-axSpA had a significantly higher prevalence of enthesitis, psoriasis, and inflammatory bowel disease (IBD). The prevalence of other SpA features was comparable between the two subgroups of axSpA. Mostly, ptreported outcomes reflecting burden of disease were comparable between the two subgroups, but BASDAI was significantly higher in the nr-axSpA subgroup (Table). Conclusions: There were a few differences between nr-axSpA and AS pts in the PROOF cohort. The clinical constellation of female sex, low CRP, enthesitis, psoriasis, and IBD in nr-axSpA pts appears to reflect a phenotype less prone to structural damage in the sacroiliac joints. However, the clinical burden of disease was comparable between the two subgroups of axSpA.

Acknowledgements: AbbVie funded the PROOF study, contributed to its design and participated in data collection, analysis and interpretation of the data, and in writing, review, and approval of the publication. Medical writing support was provided by Deepa Venkitaramani, PhD, of AbbVie.

Disclosure of Interest: D. Poddubnyy Grant/research support from: AbbVie, Janssen, MSD, Novartis, Pfizer, Consultant for: AbbVie, BMS, Boehringer, MSD, Novartis, Pfizer, and UCB, Speakers bureau: AbbVie, BMS, Janssen, MSD, Novartis, Pfizer, Roche, and UCB, R. Inman Grant/research support from: AbbVie, Amgen, and Janssen, Consultant for: AbbVie, Amgen, Janssen, Lilly, Novartis, and Pfizer, J. Sieper Grant/research support from: AbbVie, Merck, and Pfizer, Consultant for: AbbVie, Janssen, Lilly, Merck, Novartis, Pfizer, and UCB, Speakers bureau: AbbVie, Janssen, Merck, Novartis, Pfizer, Roche, and UCB, S. Akar Grant/research support from: AbbVie, BMS, MSD, Novartis, Pfizer, Roche, and UCB, Consultant for: AbbVie, BMS, MSD, Novartis, Pfizer, Roche, and UCB, Speakers bureau: AbbVie, BMS, MSD, Novartis, Pfizer, Roche, and UCB, S. Muñoz-Fernández Grant/research support from: Abbvie, BMS, Janssen, MSD, Novartis, Pfizer, Roche, and UCB, Consultant for: Abbvie, BMS, Janssen, MSD,
Table Baseline demographic and clinical characteristics of patients from PROOF cohort.

\begin{tabular}{|c|c|c|c|c|}
\hline \multicolumn{2}{|l|}{ Characteristic } & $\begin{array}{l}\text { nr-axSpA } \\
(\mathrm{N}=544)\end{array}$ & $\begin{array}{c}A S \\
(N=1039)\end{array}$ & P-value ${ }^{a}$ \\
\hline \multicolumn{2}{|c|}{ Age, years, mean \pm SD } & $35.5 \pm 9.8$ & $34.5 \pm 11.1$ & .070 \\
\hline \multicolumn{2}{|c|}{ Duration since back pain onset, months, mean $\pm S D$} & $48.7 \pm 69.2$ & $62.4 \pm 90.9$ & .001 \\
\hline \multicolumn{2}{|c|}{ Duration since diagnosis, months, mean \pm SD } & $2.8 \pm 5.6$ & $4.0 \pm 20.2$ & 119 \\
\hline \multicolumn{2}{|l|}{ Male sex, $n(\%)$} & $264(48.5)$ & $737(71.0)$ & $<.001$ \\
\hline \multirow{11}{*}{ SpA parameters } & HLA-B27 (+), n (\%) & $254(55.3)^{b}$ & $591(69.0)^{c}$ & $<.001$ \\
\hline & Inflammatory back pain, $\mathbf{n}(\%)$ & $512(94.1)$ & $991(95.4)$ & 279 \\
\hline & Peripheral arthritis, $\mathbf{n}(\%)$ & $171(31.4)$ & $343(33.0)$ & 535 \\
\hline & Enthesitis (heel), $n(\%)$ & $214(39.3)$ & $348(33.5)$ & .023 \\
\hline & Dactylitis, $n(\%)$ & $32(5.9)$ & $57(5.5)$ & .732 \\
\hline & Uveitis, $\mathbf{n}(\%)$ & $49(9.0)$ & $106(10.2)$ & 477 \\
\hline & Psoriasis, $\mathbf{n}(\%)$ & $54(9.9)$ & $59(5.7)$ & .003 \\
\hline & IBD, $n(\%)$ & $23(4.2)$ & $18(1.7)$ & .004 \\
\hline & Good response to NSAIDs, $n(\%)$ & $324(59.6)$ & $636(61.2)$ & .551 \\
\hline & Family history of SpA, $n(\%)$ & $101(18.6)$ & $196(18.9)$ & 946 \\
\hline & Elevated CRP, $\mathbf{n}(\%)$ & $178(32.7)$ & $555(53.4)$ & $<.001$ \\
\hline \multicolumn{2}{|c|}{ Number of positive SPA parameters, mean \pm SD } & $3.5 \pm 1.4$ & $3.8 \pm 1.4$ & .001 \\
\hline \multicolumn{2}{|l|}{ CRP, $m g / l$, mean $\pm S D$} & $11.5 \pm 19.5$ & $17.6 \pm 24.3$ & $<.001$ \\
\hline \multicolumn{2}{|c|}{ ASDAS-CRP, mean \pm SD } & $2.8 \pm 1.1$ & $3.0 \pm 1.1$ & .004 \\
\hline \multicolumn{2}{|c|}{ BASDAI, points NRS $(0-10)$, mean $\pm S D$} & $4.8 \pm 2.4$ & $4.3 \pm 2.3$ & $<.001$ \\
\hline \multicolumn{2}{|c|}{ Patient global, points NRS $(0-10)$, mean \pm SD } & $5.0 \pm 4.8$ & $4.8 \pm 4.6$ & 188 \\
\hline \multicolumn{2}{|c|}{ BASFI, points NRS $(0-10)$, mean $\pm S D$} & $3.4 \pm 2.5$ & $3.3 \pm 2.5$ & 815 \\
\hline \multicolumn{2}{|c|}{ SF-12V2, physical component score, mean \pm SD } & $40.9 \pm 8.9$ & $41.0 \pm 8.8$ & 698 \\
\hline \multicolumn{2}{|c|}{ SF-12V2, mental component score, mean \pm SD } & $42.9 \pm 10.9$ & $43.7 \pm 10.4$ & .166 \\
\hline \multicolumn{2}{|c|}{ WPAI-SHP - total activity impaiment, mean \pm SD } & $44.9 \pm 28.1$ & $43.1 \pm 27.4$ & 208 \\
\hline \multirow{6}{*}{ Current Treatment } & NSAIDs, $n(\%)$ & $428(78.7)$ & $800(77.0)$ & 485 \\
\hline & Methotrexate, $n(\%)$ & $40(74)$ & $63(6.1)$ & 335 \\
\hline & Sulfasalazine, $n,(\%)$ & $117(21.5)$ & $253(24.4)$ & 212 \\
\hline & Steroids, $\mathbf{n}(\%)$ & $40(7.4)$ & $85(8.2)$ & 624 \\
\hline & Analgesics, $\mathbf{n}(\%)$ & $98(18.0)$ & $144(13.9)$ & .033 \\
\hline & TNF $\alpha$ inhibitors, $n(\%)$ & $48(8.8)$ & $165(15.9)$ & $<.001$ \\
\hline
\end{tabular}

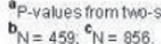

$\mathrm{nr}-\mathrm{ax} \mathrm{SPA}=$ = non-radiographic axial spondyloarthritis; $\mathrm{AS}=$ Ankylosing spondylitis; $\mathrm{SD}=$ standard deviation; $\mathrm{SpA}=$ spondyloarthrtis, $\mathrm{HLA} \cdot \mathrm{B} 27=$ human leukocyte antigen $\mathrm{B} 27 ; \mathrm{IBD}=$ inflammatory bowel disease; NSAIDs = nonsteroidal antl-inflammatory drugs; $C R P=C$-reactive protein; $A$ SDAS-CRP $=$ Ankylosing Spondylitis Disease Activit Score containing CRP; BASDAI = Bath Arkylosing Spondylitis Disease Activty Index; NRS = numeric rating scale; BASFI = Bath Ankylosing Spondylitis Functional Index, SF-12v2=Short form 12-item health survey, WPAI-SHP = Work productivity impaiment Questionnaire-specfic heath problem, TNF = fumor necrosis factor

Novartis, Pfizer, Roche, and UCB, Speakers bureau: Abbvie, BMS, Janssen, MSD, Novartis, Pfizer, Roche, and UCB, M. Hojnik Shareholder of: AbbVie, Employee of: AbbVie

DOI: 10.1136/annrheumdis-2017-eular.2001

\section{SAT0396 INVESTIGATION OF IRON DEFICIENCY ANEMIA IN ANKYLOSING SPONDYLITIS PATIENTS}

Y. Bulut ${ }^{1,2,3}$, D. Arslan Tas ${ }^{4}$, O. Goruroglu Ozturk ${ }^{2}$, U. Karaogullarindan ${ }^{3}$. ${ }^{1}$ Cukurova University, Faculty of Medicine, ADANA, Turkey; ${ }^{2}$ Biochemistry;

${ }^{3}$ Internal Medicine; ${ }^{4}$ Rheumatology-Immunology Department, Cukurova University, Faculty of Medicine, ADANA, Turkey

Background: It is reported that subclinic intestinal inflammation may occur in Ankylosing spondylitis (AS) patients, besides, using NSAIDs cause peptic and duedenal ulcers. \%50-60 of AS patients have asymptomatic ileal and colonic mucosal inflammation. It is reported that inflammatory bowel disease (IBD) is found in $5-10 \%$ of AS patients and $4-10 \%$ of IBD patients have concomittant findings with AS. These conditions may cause iron deficiency anemia (IDA).

Objectives: It is well known that chronic disease anemia is a frequent finding in AS patients. But there is no study in the literature about relationship between AS patients and IDA. In this particular study we aimed to asses frequency of IDA in AS patients and to investigate the etiologies of IDA.

Methods: Ninety four consecutive AS patients who meet 2012 ASAS/EULAR criteria, who were followed Çukurova University Romatology Clinic, were icluded. We investigated the etiologies of IDA in anemic patients. Twenty six AS patients were diagnosed as IDA. Twenty six patients without anemia were assigned as a control group. Hepcidin, soluble transferrin receptor1 (sTfR1) and anemia parameters were tested in both groups. Findings were anayzed with SPSS version 23.

Results: Twenty six of 94 AS patients were diagnosed as IDA (\%27). Frequency of IDA in our AS patients was higher when compared to the IDA prevalence in the society (\%1-2). Endoscopy and colonoscopy were performed for searching etiology of IDA. Mucosal inflammation was found in $62 \%$ of patients by endoscopy and $11 \%$ of patients by colonoscopy. One patient was diagnosed as Crohn's disease and one patient was diagnosed as Coeliac disease histopathologically. Hepcidin was found to be significantly lower in IDA patients $(p<0.01)$. We found sTfR1 levels significantly higher in IDA patients $(p<0,01)$. BASDAI (Bath Ankylosing Spondylitis Disease Activity Index) and sedimentation values were found to be higher in IDA patients statistically ( $p<0.01$ and $p=0.01$ respectively). Although we found $\mathrm{C}$ - reactive protein (CRP) values were higher when compared to the non- anemic patients; however it was not statistically significant $(p>0.05)$. Conclusions: We found higher frequency of IDA when compared to the normal 